\title{
Indícios para a história do Serviço Social a partir da Justiça de Transição
}

Clues to the history of Social Work from transitional justice Sheila de Souza Backx*

\begin{abstract}
Resumo - Este trabalho decorre da pesquisa (recente e em curso) intitulada Mulheres na linha de frente, que faz uma articulação entre violência estatal e violência de gênero às práticas de tortura perpetradas no período da ditadura civil-militar no Brasil (1964-1985), no âmbito do estado do Rio de Janeiro. No decorrer desse estudo, foram encontrados dados que possibilitam situar o Serviço Social na história - apesar de não ser seu objeto privilegiado. Assim, a partir de evidências reveladas pelo campo da Justiça de Transição pode-se melhor avaliar a participação de assistentes sociais nos movimentos de resistência desse período da formação social brasileira, a partir de um corpus documental identificado pelas Comissões de Verdade, Memória e Reparação.

Palavras-chave: Serviço Şocial; história; justiça de transição; movimento social.
\end{abstract}

\begin{abstract}
This work stems from a recent (and ongoing) research entitled Women on the front line, which links state violence and gender violence to torture practices perpetrated during the period of the civil-military dictatorship in Brazil (1964-1985), in the state of Rio de Janeiro. In the course of this study, data have been found that make it possible to situate social work in history - although not as its privileged subject. Thus, from evidence revealed by the field of transitional justice, it is possible to evaluate better the participation of social workers in the resistance movements of this period of social formation in Brazil, based on a documentary corpus identified by the Commissions of Truth, Memory and Reparation.
\end{abstract}

Keywords: social work; history; transitional justice; social movements.

\footnotetext{
* Assistente social. Doutora em Serviço Social (Puc-SP). Professora Associada na Universidade Federal do Rio de Janeiro (UFRJ). Correspondência: UFRJ - Escola de Serviço Social - Avenida Pasteur, 250 - fundos, Rio de Janeiro -RJ. CEP: 22290-902. Email: <sheilabackx@gmail.com>.
} 


\section{Introdução}

O presente trabalho decorre de dados encontrados durante o desenvolvimento da pesquisa, recente e ainda em curso, intitulada Mulheres na linha de frente: o(s) feminino(s) nos depoimentos prestados às Comissões de Memória, Verdade e Reparação no âmbito do estado do Rio de Janeiro. A citada pesquisa foi motivada a partir do entrecruzamento de vários interesses, mas, sobretudo, pela necessidade de conhecer o "não dito" sobre esse período da formação social brasileira.

Essa pesquisa toma a história como processo, estabelecendo diálogo com as evidências, de modo a atribuir significados e valores, permitindo entender os sujeitos históricos em determinados contextos e em determinada formação social; ou como, nas palavras de Thompson (1981, p. 49), um "diálogo entre conceito e evidência, um diálogo conduzido por hipóteses sucessivas, de um lado, e a pesquisa empírica por outro". Isso significa situar experiências singulares em um quadro explicativo sobre a estrutura e a dinâmica social de um determinado período em análise.

Considerando a fase inicial da pesquisa e ajudando a construir seu pano de fundo, será discutido neste trabalho como os movimentos sociais contribuíram para que, ainda que de modo incipiente, o país tivesse instaurado o que tradicionalmente se chama de Justiça de Transição - que Mezarobba (2009, p. 111) assim define:

O conceito é comumente entendido como uma estrutura para se confrontar abusos do passado e como componente de uma maior transformação política. Isso geralmente envolve uma combinação de estratégias judiciais e não-judiciais, complementares, tais como: processar criminosos, estabelecer comissões de verdade e outras formas de investigação a respeito do passado; esforços de reconciliação em sociedades fraturadas; desenvolvimento de programas de reparação para aqueles que foram mais afetados pela violência ou abusos; iniciativas de memória e lembrança em torno das vítimas; e a reforma de um amplo espectro de instituições públicas abusivas (como os serviços de segurança, policial ou militar) em uma tentativa de se evitar novas violações no futuro.

A relevância e atualidade do campo da Justiça de Transição transcende seu próprio objetivo, ao possibilitar a construção de narrativas históricas que contribuem para o entendimento de evidências em outros contextos correlatos - neste artigo em particular, a história do Serviço Social.

Assim, este artigo objetiva contribuir para a compreensão do movimento estudantil no âmbito do Serviço Social no período da Ditadura CivilMilitar brasileira, noção defendida por Netto $(2014$, p. 17) a partir da identificação dos agentes desse processo:

Levado a cabo pelos setores mais reacionários da sociedade brasileira (a fina flor da burguesia industrial e financeira, os grandes proprietários de 


\section{ReVistg all paltg}

\} INDÍCIOS PARA A HISTÓRIA DO SERVIÇO SOCIAL - BACKX, S. S.

DOI: $10.12957 /$ REP.2017.32746

terras e as cúpulas militares) e com significativo apoio inicial da alta hierarquia católica e de largas camadas da pequena burguesia, o golpe [...] contou com a mais ativa colaboração dos Estados Unidos e das empresas norte-americanas que atuavam no país [...].

Além disso, pretendemos apresentar indícios para a recuperação de outra face da Escola de Serviço Social da Universidade Federal do Rio de Janeiro.

\section{Lutas sociais por memória, verdade e justiça}

As lutas por memória, verdade e justiça no Brasil - ainda sem o uso dessa expressão, mas já traduzindo, sob diversas formas, resistência à Ditadura Civil-Militar - começaram muito antes da entrada na pauta política do país da temática dos Direitos Humanos. Assim, serão destacadas nesta seção, ainda que sinteticamente, as principais iniciativas, entre 1970 até o período da Assembleia Nacional Constituinte, promovidas por vítimas, familiares e organizações de direitos humanos e por algumas instâncias do Estado brasileiro que, após pressão de movimentos sociais, passaram a reconhecer torturas, assassinatos e desaparecimentos forçados praticados por agentes estatais.

Cabe ressaltar que, considerando a especificidade deste trabalho - contribuição do tema para o Serviço Social - somente serão lembradas as principais ações das décadas de 1990 a 2010 pautadas pela memória, verdade e justiça: busca por restos mortais em SP (Perús), Rio de Janeiro (Ricardo de Albuquerque, Cacuia e Santa Cruz) e Tocantins; pressão para transferir arquivos da comunidade de informação para o Arquivo Público do ERJ e Arquivo Nacional; cassação dos registros profissionais dos médicos que colaboraram com a Ditadura; pressão para ampliação do âmbito de atuação das várias comissões, que buscam recuperar a memória do período; e, mais recentemente, os "escrachos" na porta da residência de torturadores e colaboradores, dentre outras ações que visavam romper com a lógica da "política de esquecimento", que resultou da Lei de Anistia.

Com relação ao regime, Netto (2014) defende que o golpe de abril "não pode ser compreendido fora do contexto da guerra fria", pois, "sob o hegemonismo norte-americano e numa conjuntura em que se modificava profundamente a divisão internacional do trabalho", "os núcleos imperialistas patrocinaram a contrarrevolução preventiva em escala mundial". Chama ainda a atenção para o fato de que o golpe significou mais que "a deposição de um presidente no legítimo exercício do seu mandato - significou à época a liquidação da possibilidade de reverter a dependência e a vinculação da economia brasileira aos interesses imperialistas e de democratizar substantivamente a sociedade brasileira". Neste sentido,

ergueu-se, pois, como um Estado antinacional e antipopular, que conduziu o capitalismo no Brasil a um estágio avançado do capitalismo mono- 
polista com vigorosa intervenção estatal. Assim, ao mesmo tempo em que dominava o que parecia escapar (e, de fato, estava escapando mesmo) ao controle das classes dominantes, o golpe deflagrou uma dinâmica nova, econômica e política, que, a médio prazo, forçaria a ultrapassagem de seus próprios marcos. (NETTO, 2014, p. 74-79).

Já em meados da década de 1970, familiares de atingidos se mobilizaram para denunciar os crimes praticados pelo governo, com o apoio de diferentes atores sociais. Missas em homenagem a militantes mortos, cartas endereçadas às autoridades e campanhas internacionais ${ }^{1}$ foram algumas das formas de resistência exercidas para tornar públicas as atrocidades cometidas nos centros de prisão e tortura. A difícil via judicial também foi tentada com o intuito de responsabilizar o Estado brasileiro e obter informações sobre os desaparecimentos ${ }^{2}$. Ainda nesse período, foi estruturada a Comissão de Familiares de Mortos e Desaparecidos Políticos (CFMDP).

Em 1975 (já sob a égide da "distensão política" do Governo Geisel) teve início, em São Paulo, o Movimento Feminino pela Anistia (MFA). De início organizado por mulheres, o movimento pela anistia ganhou força em diversos setores da sociedade brasileira e passou a mobilizar grupos como movimento estudantil, Movimento Democrático Brasileiro (partido de oposição consentida ao governo militar), setores progressistas da Igreja Católica e de profissionais liberais.

A partir de 1977 são retomadas as manifestações públicas em defesa das liberdades democráticas nas principais capitais do país, nas quais a demanda pela soltura dos presos políticos tornava-se imperiosa, dando origem à criação dos Comitês Primeiro de Maio pela Anistia. Assim, em fevereiro de 1978, foi criado, no Rio de Janeiro, o Comitê Brasileiro pela Anistia (CBA), integrado por advogados, familiares, amigos de presos, exilados políticos e ex-presos políticos recém-libertos, contando com representação em diversos estados e em outros países.

Demandando uma anistia ampla, geral e irrestrita, os CBAs procuraram reorganizar os movimentos sociais pela redemocratização e buscaram popularizar a bandeira de luta, sobretudo, em torno do esclarecimento das torturas, mortes e desaparecimentos, da libertação dos presos políticos, da devolução dos restos mortais das vítimas desaparecidas, da revogação da Lei de Segurança Nacional e da responsabilização dos agentes estatais envolvidos em violações de direitos humanos. Luta à qual

\footnotetext{
${ }^{1}$ Destacam-se as denúncias promovidas por entidades de direitos humanos, como a Anistia Internacional e a Comissão Interamericana de Direito Humanos (CIDH-OEA). Em 1971 foi divulgado o documentário Brazil: a report on torture, com depoimentos de ex-presos políticos, exilados no Chile, relatando torturas.

${ }^{2}$ São exceções: a sentença da 7ำ VJF/SP, em 27 de outubro de 1978, responsabilizando a União Federal pela prisão e morte de Vladmir Herzog, e a decisão da $5^{\text {a }}$ VJF/SP, proferida em 1980, culpando o Estado brasileiro pela prisão ilegal, tortura e morte do operário Manoel Fiel Filho, em 1976.
} 


\section{ReVistg aII PaUtg}

\} INDÍCIOS PARA A HISTÓRIA DO SERVIÇO SOCIAL - BACKX, S. S. \}

DOI: $10.12957 /$ REP.2017.32746

aderiram os presos políticos ${ }^{3}$, que manifestaram repúdio à proposta de anistia apresentada pelo governo.

Em outubro de 1978, como resultado dessa pressão, o Ato Institucional n. 5 (Al-5) foi revogado, restituindo-se o direito ao habeas corpus; em dezembro, a Lei de Segurança Nacional foi reformada, extinguindo as penas de morte e de prisão perpétua, diminuindo algumas penas e determinando recolhimento dos presos políticos em local diverso do destinado aos presos comuns - assumindo-se, assim, a existência de presos políticos no Brasil. Ainda em dezembro desse mesmo ano, foi revogado o decreto de banimento de 126 exilados, mas sem contemplar os considerados "indesejados" pelo Estado (como Brizola, Arraes e Prestes).

Não se pode esquecer que, no Brasil, o pacto que levou à redemocratização teve um caráter conservador, pois "aceitava que os militares e aqueles setores que deram sustentação à ditadura permanecessem como fiadores da política durante um longo período" (SOUSA, 2002, p.1). Desta forma, após 15 anos de regime autoritário, em 28 de agosto de 1979, o Congresso Nacional promulgou a Lei n. 6.683, conhecida como Lei da Anistia, que concedia indulto a todos os que haviam cometido "crimes políticos ou conexos com estes" entre 2 de setembro de 1961 e 15 de agosto de 1979 - ou seja, crimes relacionados com crimes políticos ou praticados por motivação política.

Deve-se destacar que, apesar de aceita por segmentos da oposição, essa lei não abarcou os chamados "crimes de sangue" (terrorismo, assalto, sequestro e atentado pessoal), não beneficiando a totalidade dos presos políticos " muitos saíram um ano depois, em liberdade condicional, em função da reformulação da LSN. Também não atendeu à reivindicação dos familiares, pois nenhuma informação foi obtida " a alternativa oferecida foi um "atestado de paradeiro ignorado" ou de "morte presumida", nos casos de vítimas desaparecidas, sem que implicasse qualquer esclarecimento por parte do Estado. Na interpretação conservadora da lei, crimes praticados por policiais ou militares ficaram imunes à jurisdição penal. A Lei de Anistia foi recebida como uma vitória parcial pelos movimentos sociais.

A não resolução da demanda dos familiares dos mortos e desaparecidos políticos, nos anos de 1980, leva à busca pela verdade e justiça, bem como ao exercício de várias estratégias de pressão e divulgação de testemunhos de ex-presos e perseguidos políticos, além de busca pelos despojos dos desaparecidos que, em agosto de 1979, resulta na localização dos restos mortais de Luis Eurico Tejera Lisbôa. Nesse mesmo ano, Inês Etiene identifica e divulga o local conhecido como Casa da Morte (PetrópolisRJ) e é publicizada a versão ampliada do Dossiê sobre Mortos e Desapa-

\footnotetext{
${ }^{3}$ Ressaltam as denúncias feitas pelos presos políticos do Rio (Documento sobre a Justiça Militar) e de São Paulo (Bagulhão), bem como a Greve Nacional de Fome, iniciada em 22 de julho de 1979, no Presídio Milton Dias Moreira (Complexo Frei Caneca), que durou 32 dias e obteve a adesão de mais de 50 presos políticos, detidos em diferentes locais do país, alcançando ampla repercussão nas mídias nacionais e internacionais.
} 


\section{hevigta all pattg}

\} INDÍCIOS PARA A HISTÓRIA DO SERVIÇO SOCIAL - BACKX, S. S. \}

DOI: $10.12957 /$ REP.2017.32746

recidos Políticos. Além disso, é feita a organização da primeira caravana em busca dos restos mortais dos desaparecidos da Guerrilha do Araguaia e são localizadas, em 1991 - por moto próprio -, duas ossadas no Cemitério de Xambioá (TO), dentre outras ações.

Em 1985 (início do Governo Sarney), dava-se por encerrado o período da Ditadura Militar, com o retorno à ordem constitucional democrática, mas longe do acerto de contas com o passado. Porém, nesse mesmo ano, foi fundado, no Rio de Janeiro, o Grupo Tortura Nunca Mais (GTNM) "integrado por ex-presos e perseguidos políticos, familiares, estudantes e militantes de direitos humanos ", que se destaca na luta pela investigação, responsabilização e reparação dos crimes praticados no período da Ditadura até hoje (GRUPO TORTURA NUNCA MAIS, 1995). Nesse mesmo ano, é publicado o livro Brasil: nunca mais, resultado de extensa pesquisa iniciada em 1979, objetivando o registro das violações de direitos humanos do período ditatorial, com base nos Inquéritos Policial-Militares (IPMs).

Com o processo constituinte, as lacunas da denominada Lei de Anistia são rediscutidas, derivando na redação do Art. $8^{\circ}$ do Ato das Disposições Constitucionais Transitórias (ADCT), único dispositivo da Constituição Federal de 1988 a tratar da anistia. Esse artigo reafirmou o direito à promoção aos servidores públicos atingidos pelo golpe (EC 26/85), estendendo-o a trabalhadores do setor privado (especificamente aeronautas), e definiu a possibilidade de reparação econômica ao anistiado. Este artigo é um marco legal no que se convencionou chamar internacionalmente de Justiça de Transição.

Neste sentido, as Comissões de Verdade e de Reparação (e similares), ao funcionarem com outras instituições que compõem a Justiça de Transição, revelam e exigem que as "verdades reveladas" sejam reconhecidas como "verdades judiciais", a partir de depoimentos e, sobretudo, a abertura dos arquivos da chamada "comunidade de informação". Assim, é denominado um verdadeiro complexo de instituições que, até 1968, integravam a repressão política oficial: SNI, CIE, Cenimar, Cisa, outras seções de unidades militares, as chamadas divisões de segurança e informação de toda a estrutura governamental, empresas e autarquias, órgãos das secretarias estaduais de segurança pública (Dops), as polícias militares e estaduais, bem como o Departamento de Polícia Federal. A partir de 1968, esse sistema é redimensionado, passando a contar com recursos oferecidos por empresários. São marcos desse período a criação da Oban, que se articula a partir de 1970 ao Codi/DOI. ${ }^{4}$

Por também ajudar a revelar essa estrutura, as Comissões da Verdade "fazem parte de um processo no qual se interpenetram os direitos à memória, à verdade, à justiça e à reparação" (RIO DE JANEIRO, 2015, p.

${ }_{4}^{4}$ Para mais detalhes, ver: Netto (2014, p. 136-137). 
11), ao romperem com a "política do esquecimento" que perdurou durante cinco décadas no Brasil.

\section{Serviço Social e resistência}

Como é sabido, vários assistentes sociais participaram de movimentos de resistência à Ditadura Civil-Militar, com maior ou menor intensidade e de formas variadas (CFESS, 2017). Contudo, durante muito tempo, havia certa cautela no trato desse assunto, seja por parte daqueles que participaram das várias ações, seja por parte dos seus diversos interlocutores. Além disso, para se falar mais abertamente sobre o tema, muito concorreram as várias ações deflagradas e instâncias criadas no movimento pelo direito à memória.

Particularmente interessante é analisar o que emerge como decorrência do livre acesso aos arquivos das polícias políticas, em seus variados níveis e regiões do país, bem como depoimentos prestados às Comissões de Verdade e Reparações, dentre outras.

Para os limites deste trabalho, pretende-se enfatizar duas peças distintas: o acervo da polícia política paulistana sobre as estudantes fichadas no evento conhecido como Congresso de Ibiúna (1968) e um depoimento prestado à Comissão da Verdade do Estado do Rio de Janeiro (CEV-Rio), que integra o Relatório Final dessa Comissão.

\section{Sobre as participantes do Congresso de Ibiúna}

Vale situar, ainda que sumariamente, a situação do movimento estudantil no período da Ditadura Civil-Militar, a partir de sua organização mais conhecida: a União Nacional de Estudantes (UNE). Essa entidade criada ao final dos anos 1930 - assume, no início dos anos 1950, nos dizeres de Netto (2014, p. 46), uma "política direitista". Contudo, a partir de 1956, "volta a protagonizar importante papel progressista" e, na "entrada dos anos 1960", sua influência "incide para além dos limites acadêmicos". Essa mudança de orientação não se daria de modo isolado, pois estaria no contexto de "renovação e mobilização do 'mundo da cultura'".

Contudo, essa guinada não se deu sem tentativas de contenção: em julho de 1962, durante a realização de Congresso em Petrópolis, os participantes foram atacados "a tiros por militantes da extrema-direita e oficiais do Exército; e, em junho de 1964, a UNE foi formalmente extinta pelo Ministro da Educação da ditadura" (NETTO, 2014, p. 89, p. 101).

No que toca ao movimento estudantil, desde 1964 a ditadura, com o largo emprego das suas medidas de força (a perseguição aos seus líderes, 
a já mencionada extinção formal da UNE - bem como das suas organizações em nível estadual, as Uniões Estaduais de Estudantes/UEEs e nas universidades, os Diretórios Acadêmicos/CAs/Das - pelo governo Castelo Branco), demonstrou-se absolutamente incapaz para conquistar qualquer legitimidade. A nova estrutura que a ditadura tentou impor aos estudantes (através da 'Lei Suplicy', de 9 de novembro de 1964, criando o Diretório Nacional de Estudantes/DNEs, os Diretórios Estaduais de Estudantes/DEEs, os Diretórios Centrais dos Estudantes/DCEs e os Diretórios Acadêmicos/ DAs) nunca teve existência real. Passados os primeiros meses da ditadura, a UNE e praticamente toda a sua estrutura, em escala nacional, voltou a funcionar; ilegal e perseguida, realizou quatro congressos clandestinos, ganhou mais influência, liderou a luta contra os acordos MEC-USAID, já referidos, enfrentou o assalto à autonomia universitária empreendido pelos governos oriundos do $1^{\circ}$ de abril e seu papel cresceu na resistência democrática. E a oposição estudantil à ditadura estendeu-se para além dos círculos universitários: também no ensino secundário e no ensino técnico, as organizações estudantis marcaram nítida oposição contra o regime e se mobilizaram contra ele. No que diz respeito ao repúdio à ditadura por parte dos estudantes universitários, sem dúvidas expressava o peso da tradição combativa da UNE, que vinha dos tempos do Estado Novo; mas também era parte do grande repúdio que os intelectuais e, mais amplamente, o 'mundo da cultura' devotaram à ditadura [...]. (NETTO, 2014, p. 110).

O $30^{\circ}$ Congresso da UNE, realizado em outubro de 1968, na Região Sul do estado de São Paulo, no município de Ibiúna, contava com a participação de mais de mil estudantes universitários - número extremamente alto para uma operação clandestina, realizada em um sítio ("Mucuru", na encosta da Serra de São Sebastião) na área rural.

Como uma das atividades principais do encontro, estava programada a eleição da nova direção da UNE, que iria definir os rumos do movimento estudantil. A luta pela presidência estava especialmente acirrada. De um lado, José Dirceu, ex-presidente da União Estadual de Estudantes (UEE) de São Paulo e, de outro, Jean Marc, ex-presidente do Centro Acadêmico da Faculdade de Química da Universidade Federal do Rio de Janeiro.

Estudantes de vários estados convergiram a Ibiúna; apesar das tentativas para não chamar atenção ${ }^{5}$, a compra de gêneros em elevada quantidade gerou comentários em uma localidade com somente seis mil habitantes - que não hesitaram em denunciar a movimentação.

Segundo o jornal Folha de São Paulo, depois de avançarem "alguns quilômetros de carro e outro trecho a pé, por causa da lama da estrada, 215 policiais chegaram ao local às 7h15" de sábado, "organizaram o cerco aos estudantes e dispararam algumas rajadas de metralhadora para o ar, para

\footnotetext{
${ }^{5}$ Estudantes, em grupos de dez a vinte pessoas, viajaram da capital para Piedade, em ônibus com partida de hora em hora; desciam em Ibiúna e eram transportados em jipes até o local do congresso (FOLHA DE SÃO PAULO, 1968). Mesmo com essa preocupação, fica evidente a violação de normas elementares de segurança.
} 


\section{ReVistg aII PaUtg}

\} INDÍCIOS PARA A HISTÓRIA DO SERVICYO SOCIAL - BACKX, S. S. \}

DOI: $10.12957 /$ REP.2017.32746

intimidá-los. Sem resistir, os congressistas foram colocados em fila e levados aos ônibus requisitados para transportá-los para a capital".

Todos os participantes foram presos no sábado, dia 12 de outubro, por soldados da Força Pública e policiais do Departamento de Ordem Política e Social (Dops) de São Paulo. Toda a liderança do movimento universitário foi presa: o presidente da União Estadual de Estudantes (UEE), o presidente da UNE, o presidente da União Metropolitana de Estudantes (UMEs), o presidente do DCE da UFRJ e o presidente da União Paulista de Estudantes Secundários, entre outros. Eles foram levados diretamente ao Dops, passando posteriormente por vários locais (quartéis de Itaipu e São Vicente, delegacia de Vila Mariana e pelo $4^{\circ} \mathrm{RI}$ ). Os demais foram "recolhidos" ao presídio Tiradentes.

Na ocasião, o então governador daquele estado (Abreu Sodré), em atividade oficial no Horto Florestal de São Paulo, teria declarado que agiu para "reprimir a agitação e a subversão" quando determinou, "após horas de angustia e apreensão, a prisão de estudantes subversivos que participavam do congresso da UNE" (FOLHA DE SÃO PAULO, 1968).

Com a abertura dos arquivos da chamada "comunidade de informações", o sítio eletrônico intitulado Documentos Revelados $(2014)^{6}$ organizou um arquivo especial intitulado Mulheres de Ibiúna. Esse arquivo contém as fotos de identificação de 152 jovens que foram presas no $30^{\circ}$ Congresso de Ibiúna, em ordem alfabética, e sua atenta observação revela alguns dados instigantes.

Apesar de o relato da Folha de São Paulo (1968) indicar que as primeiras a embarcarem foram "as moças" ${ }^{\prime 7}$, essas não foram as primeiras a serem atendidas, pois seus números variam de 1.041 a 1.210 (em dez fotos, não é possível visualizar a identificação, pois a placa estava muito baixa " dado que, por um lado, evidencia a dificuldade de "fichar" tantos jovens, fazendo com que o fotógrafo não conseguisse atentar para todos os detalhes, e, por outro, o sucesso de participação nesse congresso). Evidentemente, foram identificadas, juntamente com a parte final do grupo masculino.

Analisando-se a procedência das participantes por idade, pode ser observado que a grande maioria das jovens era proveniente dos estados de São Paulo (21\%) e Rio de Janeiro (20,4\%), seguida por Bahia (11,8\%) e Minas Gerais (10,5\%). As idades variavam de 18 a 37 anos, com grande concentração entre 18 e 22 anos (59\% das participantes), seguida pela faixa de $23-27$ (29\%).

Das 152 jovens, somente uma parece não ser estudante (foi identificada como revisora de provas tipográficas, paulista, 28 anos, residente em São Paulo; contudo, poderia ser aluna secundarista). Também foi encon-

\footnotetext{
${ }^{6}$ Esse sítio eletrônico tem por objetivo expor documentos emitidos pela denominada "comunidade de informações", que se constituiu no período de 1964 a 1985. O site é editado por Aluízio Palmar, ex-integrante do MR-8 e também um dos atingido pelo estado ditatorial brasileiro.

${ }^{7}$ Há também o relato de transporte especial e atendimento médico a uma jovem que seria paraplégica - essa teria sido a primeira a embarcar em um jipe do exército, após transporte de maca.
} 


\section{hevigta all pattg}

\} INDÍCIOS PARA A HISTÓRIA DO SERVIÇO SOCIAL - BACKX, S. S. \}

DOI: $10.12957 /$ REP.2017.32746

trada uma aluna secundarista (18 anos, mineira, residente em Belo Horizonte, única a ter registrado tanto o seu nome de solteira como o de casada - o que indica a possibilidade de todas as outras serem solteiras, mas não necessariamente sem companheiros).

Objetivando analisar o perfil das participantes em função dos cursos universitários frequentados, passou-se a trabalhar com o universo de 150 estudantes de curso superior (ou seja, nem a jovem identificada como revisora nem a secundarista foram consideradas). E aqui surgem mais dados interessantes.

Os cursos com maior participação das jovens foram, respectivamente, Filosofia (24\%), Serviço Social (17,3\%), Direito (7,3\%) e Medicina $(5,3 \%)$. No total, 27 cursos $^{8}$ estavam representados no Congresso de Ibiúna, somente consignando a participação feminina. Cabe também ressaltar que não houve registro do curso em 15 identificações $(10 \%)$, só tendo sido indicada a instituição de ensino da jovem (caso no qual se situa a hoje professora da PUC-SP Maria Beatriz Costa Abramides). Tal fato pode indicar que a participação de estudantes de Serviço Social pode ter sido maior, considerando que várias não identificadas são de Brasília, que congregou bastantes alunas de Serviço Social e somente uma jovem do curso de Geologia.

Ademais, deve-se considerar que, à época do congresso, a Reforma Universitária ainda não havia sido aprovada. Ela foi instituída através da Lei 5.540, de 28 de novembro de 1968. Teve por base os acordos MEC-Usaid, realizados entre 1965 e 1966, que são exemplos de subordinação do Brasil aos interesses norte-americanos. Além disso, constituíram-se, também, em "programas de ajuda" - meio legal de aumentar a ação estadunidense em seu projeto de "contrarrevolução preventiva". Vale ainda lembrar que, "em 1962, o sistema universitário brasileiro compreendia 40 universidades: 23 federais, 3 estaduais e 14 particulares" (NETTO, 2014, p. 272). A partir da reforma, multiplicam-se "as instituições particulares, de natureza empresarial" (NETTO, 2014, p. 108).

Desse modo, como a reforma ainda não havia sido feita, os cursos de Filosofia estavam, portanto, mais vinculados às licenciaturas em várias áreas do conhecimento do que a formação em nível de bacharelado. Tomando-se essa hipótese como verdadeira, o curso de Serviço Social seria o que concentra a maior participação.

No caso do Serviço Social, somente a Região Norte não estava representada; as demais apresentaram os seguintes índices de participação, em ordem de grandeza: Região Sudeste (53,9\% " contando com os seguintes estados: Espírito Santo, Minas Gerais, Rio de Janeiro e São Paulo), Região Nordeste (30,8\% “ Bahia, Ceará, Maranhão, Paraíba, Pernambuco e Sergipe),

\footnotetext{
${ }^{8}$ Em ordem alfabética: Administração, Arquitetura, Artes Plásticas, Biblioteconomia, Comunicação, Dança, Desenho (licenciatura), Direito, Economia, Educação Familiar, Enfermagem, Engenharia, Farmácia, Filosofia, Geologia, História, Letras, Medicina, Música, Nutrição, Odontologia, Pedagogia, Psicologia, Química, Serviço Social, Teatro e Especialização em Educação Física (PG lato sensu).
} 


\section{ReVistg all paltg}

\} INDÍCIOS PARA A HISTÓRIA DO SERVIÇO SOCIAL - BACKX, S. S. \}

DOI: $10.12957 /$ REP.2017.32746

Região Centro-Oeste (11,5\% " Goiás e Brasília) e Região Sul (3,8\% " contando apenas com Santa Catarina).

Evidentemente, a maior participação da Região Sudeste não pode ser valorizada, em função de ser a Região que sediou o evento, mas se deve destacar que no grupo das "Meninas de Ibiúna" ${ }^{9}$ o estado do Espírito Santo (assim como o estado do Maranhão) só está consignado por representantes do curso de Serviço Social.

Corroborando a hipótese, vale comentar os dados para o curso de Filosofia, que apresentou resultados melhores para as Regiões Nordeste (33,3\% " com predominância no estado da Bahia) e Sul (16,6\% " com participação do Rio Grande e Paraná). A Região Sudeste teve apenas 47,4\% de participação, com concentração no estado de São Paulo (33,3\%) - situação distinta da apresentada para o curso de Serviço Social.

Vale conhecer as instituições de ensino de Serviço Social às quais as jovens estavam vinculadas, conforme registro na ficha de identificação, por estado: Bahia - Faculdade/Escola de Serviço Social da Universidade Católica de Salvador; Ceará - Curso de Serviço Social de Fortaleza; Distrito Federal "Faculdade de Serviço Social de Brasília; Espírito Santo " Faculdade de Serviço Social de Vitória; Escola de Serviço Social do Espírito Santo; Goiás - Faculdade de Serviço Social da Universidade de Goiás; Maranhão - Curso de Serviço Social da Universidade do Maranhão; Minas Gerais Faculdade de Serviço Social de Juiz de Fora; Faculdade de Serviço Social da Universidade Católica de Minas Gerais; Faculdade de Serviço Social de Minas Gerais; Paraíba " Faculdade de Serviço Social da Paraíba; Faculdade de Serviço Social de João Pessoa; Pernambuco "Escola de Serviço Social de Pernambuco; Santa Catarina - Faculdade de Serviço Social de Florianópolis; Sergipe "Faculdade de Serviço Social da Universidade Feral de Sergipe; Rio de Janeiro "Escola de Serviço Social da Universidade Federal Fluminense; Curso de Serviço Social da Universidade Federal do Rio de Janeiro; Faculdade de Serviço Social da Universidade Federal da Guanabara; São Paulo "Pontifícia Universidade Católica de São Paulo; Faculdade de Serviço Social de Campinas; Faculdade de Serviço Social de Piracicaba.

Observando-se os nomes das instituições de ensino arroladas, pode ser verificado que nem sempre a informação era colhida com o mesmo esmero (caso da Universidade Católica de Salvador, que ora era designada Faculdade de Serviço Social, ora Escola de Serviço Social) ou a ignorância do agente responsável pelo registro (salta aos olhos a Universidade Federal da Guanabara - quando, a rigor, era Universidade do Estado da Guanabara, que atualmente é a Universidade do Estado do Rio de Janeiro - Uerj).

Em relação ao Rio de Janeiro, também chama atenção a presença de algumas instituições de ensino, pois é consensual, entre alunas do pe-

\footnotetext{
${ }^{9}$ Esse material é também assim conhecido - denominação que consideramos mais adequada em função dos dados, já apresentados, relativos à faixa-etária.
} 
ríodo ${ }^{10}$, o maior envolvimento do Curso de Serviço Social da Universidade Federal Fluminense no movimento estudantil. Não se tem detalhes sobre o processo de escolha dos delegados com seus respectivos quantitativos, mas foram encontradas duas alunas da UFF, uma da UFRJ e uma da Uerj. Esses dados precisam ser retomados e esclarecidos para melhor se entender a organização e a participação das alunas de Serviço Social no movimento estudantil no estado do Rio de Janeiro nesse período.

\section{A ESS/UFRJ e o relatório da Comissão Estadual da Verdade do Rio de Janeiro}

Da mesma forma que se aponta o maior envolvimento das alunas da UFF com o movimento estudantil, também é recorrente o discurso que remete ao conservadorismo da ESS/UFRJ, que se expressaria, sobretudo, através da composição de seu quadro docente. Contudo, o relatório final da CEV-Rio traz indício bastante relevante para iluminar aspecto ainda não conhecido sobre essa unidade de formação.

A CEV-Rio foi instalada em 8 de maio de 2013, sendo composta por sete membros, contando com grupo de assessores e pesquisadores que auxiliaram no desenvolvimento das várias atividades realizadas até 13 de novembro de 2015 - quando foi apresentado o relatório final. Nesse período, a CEV-Rio se dedicou

ao esclarecimento de casos de prisão ilegal, tortura, morte, desaparecimento forçado e ocultação de cadáver, ocorridos no estado do Rio de Janeiro, especialmente a partir do golpe de 1964, e procurou identificar as estruturas, os locais e as instituições relacionadas às sistemáticas violações de direitos humanos. [...] documentar as violações de direitos humanos cometidos durante a ditadura, conferindo centralidade à memória das vítimas e dos grupos sociais atingidos pela violência estatal. Denuncia ainda as continuidades de um passado que se atualiza constantemente no presente e evidencia os obstáculos para a efetivação do Nunca Mais. As recentes intervenções das Forças Armadas no espaço urbano, a implementação de políticas de segurança pública guiadas pela lógica de combater um 'inimigo interno', a criminalização dos movimentos sociais e o monopólio dos grandes grupos de comunicação, entre uma série de outras questões são apenas algumas das marcas da ditadura que persistem no nosso cotidiano. Espera-se que suas páginas possam ajudar a fortalecer as lutas políticas que, ainda hoje, enfrentam o legado autoritário do regime militar, abrindo caminho para o avanço da democracia. (RIO DE JANEIRO, 2015, p. 18-19).

\footnotetext{
${ }^{10}$ Depoimento informal prestado por ex-alunas da UFRJ e da UFF - membros dos respectivos Centros Acadêmicos " ao Centro de Memória da ESS/UFRJ (CeMDESS), em reunião realizada em 2010, na casa da Assistente Social Tereza Vilella (Rio de Janeiro/RJ).
} 


\section{ReVistg aII PaUtg}

\} INDÍCIOS PARA A HISTÓRIA DO SERVICYO SOCIAL - BACKX, S. S. \}

DOI: $10.12957 /$ REP.2017.32746

Esse documento se estrutura em seis partes ${ }^{11}$, que se desdobram em 24 capítulos. A seção 12 (Vozes despertadas) " que integra a terceira parte do relatório final " objetiva registrar os depoimentos dos que procuraram espontaneamente a comissão para narrar a violência do período - "vozes silenciadas por tanto tempo" que foram assim interpretadas pela CEV-Rio:

Inseridas no doloroso processo de construção da verdade, as narrativas dão voz àqueles que foram perseguidos, impedidos de exercer suas profissões, presos e torturados, bem como aos que foram privados de conviver com seus familiares mortos ou desaparecidos pela repressão. Os relatos apresentam uma pequena fração do enorme grupo de pessoas afetadas pelo terror de Estado e que permaneciam 'anônimas' em nossa história oficial. Os depoentes transmitiram a necessidade de contar aos outros o que havia acontecido em suas vidas, atribuindo um valor pedagógico, político e reparatório ao ato de testemunhar. As narrativas apresentadas evidenciam que, apesar de transcorridas décadas do fim da ditadura militar, o silêncio, o incômodo e o medo dos atingidos de contarem suas histórias de vida são marcas ainda presentes no processo de transição brasileiro. Na medida em que se abre uma porta para o testemunho, percebe-se que a multiplicidade da violência foi tão variada quanto a quantidade dos sujeitos atingidos, assim como são múltiplas as estratégias de superação da dor. O ato de narrar o trauma, de colocar em palavras as experiências vividas no contexto de violações tão profundas, busca superar a dificuldade de se transmitir histórias até então inseridas no âmbito da vida privada dos indivíduos e situadas, muitas vezes, no campo do indizível, do inenarrável, tamanha dor e violência sofridas [...]. (RIO DE JANEIRO, 2015, p. 160 " grifos nossos).

Nesse contexto, a comissão acolheu a demanda de Thereza Álvares Vidigal (ouvida em 4 de abril de 2014), que buscou a CEV-Rio com o objetivo de esclarecer as circunstâncias da morte de seu companheiro, João Fortunato Vidigal, encontrado morto em sua residência, em 30 de dezembro de 1972. Em função do pleito apresentado, o registro coloca no centro da cena a biografia e trajetória de João Fortunato Vidigal, que ainda era estudante (Psicologia/UFMG) quando se casou com Thereza, em 1965. Apesar do levantamento de mais informações, o caso João Fortunato Vidigal ainda permanece aberto.

Porém, para os propósitos do presente trabalho, destaca-se a trajetória de Thereza, cujos poucos dados aparecem indiretamente no relatório:

Em abril de 1966, após Thereza ser presa por agentes do DOPS e do CENIMAR em Minas Gerais e libertada por meio de habeas corpus impetrado pelo advogado Sobral Pinto, ela e João vieram para o Rio de Ja-

\footnotetext{
${ }_{11}$ A saber: sobre a CEV-Rio, O Golpe de 1964 e a Ditadura, Violência e terror do estado, A estrutura do estado ditatorial, Autoria das graves violações de Direitos Humanos e $O$ que resta da ditadura.
} 
neiro, onde passaram a trabalhar no Banco da Providência. Thereza foi contratada como professora nos cursos de Serviço Social da Pontifícia Universidade Católica do Rio de Janeiro (PUC-Rio) e da Universidade Federal do Rio de Janeiro (UFRJ), e João continuou seus estudos de psicologia na UFRJ e, posteriormente, no curso de Pedagogia da Universidade do Estado do Rio de Janeiro (UERJ). (RIO DE JANEIRO, 2015, p. 165 “ grifos nossos).

Em contato com docentes aposentados dessa unidade acadêmica (que ingressaram ao final da década de 1970), verificou-se o desconhecimento dessa história; assim, chegou-se a pensar que não se tratava de docente com formação em Serviço Social. Contudo, em busca realizada através do site Google (ASSOCIAÇẪO NACIONAL, 2014) ${ }^{12}$, foi verificado que Thereza é assistente social aposentada do Banco Nacional de Habitação (BNH), onde trabalhou com habitação popular, e foi representante da Associação dos Funcionários do $\mathrm{BNH}$ no Estado de Minas Gerais (quando retornou para seu estado natal).

Em relação à docência, há informação de que foi Professora Assistente da Cadeira de Desenvolvimento e Organização Comunitária na PUC/ RJ e, na ESS/UFRJ, teria ministrado as disciplinas de Serviço Social de Comunidade e Serviço Social de Grupo. Evidentemente, esse também é outro indício que, se verificado, pode contribuir para recuperar aspectos não conhecidos da trajetória dessa unidade de ensino.

\section{Considerações finais}

A luta por verdade e justiça ainda não acabou, apesar das instâncias judiciais e não judiciais que já foram estabelecidas, como mostram as novas estratégias e ações desenvolvidas pelos militantes dessa área. Vale registrar que o direito à memória e à verdade foi estabelecido como um dos sete eixos do Programa Nacional de Direitos Humanos (PNDH3), que recomendou a criação de uma Comissão Nacional da Verdade, com a tarefa de examinar as violações de direitos humanos praticadas por agentes estatais no contexto da repressão política da Ditadura. A criação dessa comissão permitiu, efetivamente, a abertura dos arquivos da "comunidade de informação", possibilitando reescrever o nosso passado recente.

Como se tentou demonstrar ao longo deste artigo, a história do Serviço Social pode se beneficiar com a abertura dos arquivos da comunidade de informação, através dos procedimentos relativos ao que se convencionou chamar de Justiça de Transição, aliada à proposta de uma história escrita de "baixo para cima". De fato, o material organizado a partir do

\footnotetext{
${ }^{12}$ Nesse informativo, uma súmula da trajetória funcional de Thereza desde 1966 é narrada na seção Personalidade. Participou dessa busca a professora aposentada Maria Helena Rauta Ramos.
} 


\section{ReVistg all paUtg}

\} INDÍCIOS PARA A HISTÓRIA DO SERVIÇO SOCIAL - BACKX, S. S. \}

DOI: $10.12957 /$ REP.2017.32746

acervo da polícia paulistana sobre o Congresso de Ibiúna apresenta dados até então só conhecidos de modo impreciso. Sabia-se, sem dúvida, da participação de "vários alunos" de Serviço Social. Agora, sabe-se quantas e quais alunas participaram, seus estados de procedência e o nível de organização do movimento estudantil da época: quase todos os estados brasileiros estavam representados e, no caso particular do Rio de Janeiro, a presença de aluna da ESS/UFRJ causa surpresa.

Considerando-se a participação masculina e a possibilidade de identificar o curso de todas as alunas "fichadas", provavelmente a representação do Serviço Social pode ser maior. Também provoca espécie exdocente dessa mesma unidade de formação que tenha passado pelo Dops e pelo Cenimar/MG.

Os indícios aqui apresentados apontam para a possibilidade de descobertas de novos dados para a história do Serviço Social, em particular no Rio de Janeiro. Espera-se que pesquisadores interessados na trajetória do Serviço Social aproveitem a divulgação dessas informações para reexaminar aspectos não conhecidos das unidades de formação, da organização estudantil e de profissionais em suas organizações de trabalho que possibilitem iluminar lacunas da historiografia profissional, através da voz dada aos anônimos que ajudaram a escrever essa história. 


\section{Referências}

ASSOCIAÇÃO NACIONAL dos Ex-empregados do BNH Participantes de Planos de Previdência (Anaphab). Informativo. Ano XI, N. 42, 1ํㅡ e $2^{\circ}$ trim. 2014.

BRASIL. Constituição (1988). Ato das Disposições Constitucionais Transitórias, de 05 de outubro de 1988. Constituição da República Federativa do Brasil: promulgada em 05 de outubro de 1988: atualizada até a Emenda Constitucional no 20, de 15 de dezembro de 1998. 21ํㅡㄹ. ed., São Paulo: Saraiva, 1999. pp. 141-175.

BRASIL. Lei 5.540, de 28 d novembro de 1968. Fixa normas de organização e funcionamento do ensino superior e sua articulação com a escola média e dá outras providências. Diário Oficial [da] República Federativa do Brasil: Brasília: Distrito Federal, 03 dez 1968. Disponível em: <www.planalto. gov.br/ccivil_03/leis/L5540.htm> Acesso em: 10 jun. 2016.

BRASIL. Lei 6.683, de 28 de agosto de 1979. Concede anistia e dá outras providências. Diário Oficial [da] República Federativa do Brasil. Brasília, Distrito Federal, 28 dez. 1979. Disponível em: <www.planalto.gov.br/ ccivil_03/leis/l6683.htm>. Acesso em: 22 abr. 2015.

BRASIL. Secretaria de Direitos Humanos da Presidência da República. Plano Nacional de Direitos Humanos (PNDH-3). Brasília: SDH/PR, 2010.

CFESS. Serviço Social, memórias e resistências contra a ditadura: depoimentos. Brasília: CFESS, 2017.

DOCUMENTOS REVELADOS. As meninas de Ibiúna: 152 fotografias das estudantes presas no Congresso de Ibiúna. 2014. Disponível em: <http:// www.documentosrevelados.com.br/repressao/as-meninas-de-ibiuna-152fotografias-das-estudantes-presas-no-congresso-de-ibiuna/>. Acesso em: 12 mai. 2016.

FOLHA DE SÃO PAULO. Banco de dados - Acervo on-line. 1968. Disponível em: <http://almanaque.folha.uol.com.br/brasil_13out1968.htm>. Acesso em: 10 mar. 2015.

GRUPO TORTURA NUNCA MAIS. Dossiê dos mortos e desaparecidos políticos a partir de 1964. Recife: Companhia Editora de Pernambuco, 1995. MEZAROBBA, G. De que se fala quando se diz "Justiça de Transição"? BIB, São Paulo, n. 67, 1ํㅗ. 2009.

NETTO, J. P. Pequena história da ditadura brasileira (1964-1985). São Paulo: Cortez, 2014.

RIO DE JANEIRO (Estado). Comissão da Verdade do Rio. Relatório/Comissão da Verdade. Rio de Janeiro: CEV-Rio, 2015. 
SOUSA, J. J. V. de. Memória e esquecimento: artimanhas da história. Rio de Janeiro: DHNet, 2002. Disponível em: <http://www.dhnet.org.br/dados/ acesso/texto/index.html>. Acesso em: 18 dez. 2015.

THOMPSON, E. P. A miséria da teoria ou um planetário de erros - uma crítica ao pensamento de Althusser. Rio de Janeiro: Zahar, 1981.

DOI: $10.12957 /$ rep.2017.32746

Recebido em 25 de agosto de 2017.

Aprovado para publicação em 16 de novembro de 2017.

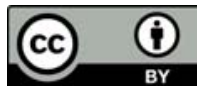

A Revista Em Pauta: Teoria Social e Realidade Contemporânea está licenciada com uma Licença Creative Commons Atribuição 4.0 Internacional. 